\title{
An Investigation into the Sociolinguistics of Asu Personal Names in Same, Tanzania
}

\author{
Aaron Kileng'a \\ School of Education, University of Arusha, Tanzania \\ "Corresponding author: aaronfurahi@gmail.com
}

\begin{abstract}
Many Ethnic Community Languages (ECLs) in Tanzania are demographically and socioculturally pressured mainly by Kiswahili and English to a lesser extent. The ECLs which were previously used in elementary education, local administration and religious activities currently do not have any place in any official domain and thus are limited to home and other few immediate domains. Due to this unequal coexistence of the languages, many ECLs are considered endangered, calling for efforts from stakeholders to prevent the death of such a precious cultural heritage. By documenting the social aspects of Asu personal names, this paper is a contribution to such initiatives like The Languages of Tanzania Project aiming at documenting Tanzanian ECLs in every possible area and means. The paper used participant observation, in-depth interview and self-intuition to investigate personal names of a Bantu speaking people called Vaasu (Asu) of Northern Tanzania, considering naming as an important aspect of the society. The paper looked at Asu names within the purview of linguistic anthropology considering names as not being arbitrary labels but sociocultural tags that have sociocultural functions and meanings. By using thematic analysis technique, the paper analysed and discussed the typology of the names including family names, circumstantial names, theophorous names, flora and fauna names, to mention but a few. The paper further examined the changing nature of Asu naming system and practice as dictated by cultural contact mainly with Swahili and Christian/ western culture. The paper eventually recommends for further investigation on issues surrounding naming practices and strategic measures to prevent this important African cultural resource.
\end{abstract}

Key words: Chasu (Asu), Sociolinguistics, Vugwama, Personal Names

\section{Introduction}

A name is what somebody or something is called after. It is a term or phrase by which somebody or something is known and is distinguished from other people or things (Chamber Dictionary, 2005). Abdulganiy et al (2015) note that name is a word or words by which an individual person, place or thing is identified. It is the nomenclature used in making reference to all things; tangible or intangible, living or non-living, concrete or abstract, liquid or solid.

The study of personal names and naming system is referred to as anthroponomy, a field which is related to genealogy, sociology and anthropology. Under the umbrella of onomastics, a field dealing with the study of proper names, anthroponomy investigates names in their forms, meanings and use aspects (Agyekum, 2006). In human sociocultural contexts, naming is done in order to differentiate, to recognize and finally to know.

The topic of names is a multidisciplinary one that has occupied the attention of philosophers of language, anthropologists, linguists and ordinary people. Personal names can best be analyzed by a combination of both philosophical and anthropological notions. Societies attach much importance to names and their naming practices. This goes without saying that the knowledge about names gives insight into culture, philosophy, thought, environment, religion and language of particular societies. In the same line of argument, 
symbolic nature of traditional names and their interpretation depicts religious beliefs of a given society and their interaction with foreign cultures. In this line of understanding, the objective of this paper was to investigate the semantic aspects, naming criteria, typology and gender relations in Asu personal names.

\section{Chasu and its speakers (the Asu People)}

Languages in Tanzania are grouped into Bantu, Nilotic, Cushitic and Khoisan. Of the four, Bantu languages are spoken by the largest number of speakers occupying most of the western, southern, eastern and central parts of the country. The Nilotic group comes second with languages like Maasai, Luo, Datoga and Okiek spoken in North Eastern Tanzanian people. Cushitic group has to do with languages like Iraqw, Assax, Gorowa, Alagwa and Burunge spoken in pockets near Central Tanzania. The Khoisan languages which include Sandawe and Hadza are spoken in areas bordering Cushitic. This linguistic distinction also designates sociocultural distinction in the country. This anthroponomic investigation focuses on Chasu, one of the Bantu Ethnic Community Languages spoken in Northern Tanzania.

Chasu is spoken by the Asu people (Vaasu) who live in Vuasu (externally referred to as Pare) land extending approximately from 60 to 70 miles southeastward from Kilimanjaro along the northern banks of Pangani River. Most of the population live on the Pare Mountains and hence referred to as the mountaineers. Vuasu covers two administrative districts of Mwanga and Same in the north-eastern Kilimanjaro region of Tanzania.

Authors identify two major dialects of the language distributed among the two administrative districts mentioned above (Kileng'a 2015, Sebonde 2009 \& Mreta 1998); Northern Chasu is spoken in Mwanga District while Southern Chasu is spoken in Same. The areas are also distinguished as mpare ya ugu 'upper pare' and mpare ya ishi 'lower pare' respectively.

\section{Related Literature and Studies}

This part presents review of literature and studies that informed the author in the process of writing.

\section{Theoretical Framework}

This paper takes the aspect of linguistic anthropology and sociolinguistics basing on the theory that there is a strong interface between people's language and their cultural practices. In this presupposition, the premise is that language is not only used as a cultural resource and practice, but it is also envisioned as a powerful tool used to view and understand the worldview and philosophy of a particular society. Agyekum, (2006) stresses that language can be used as a microscopic lens to view and understand the social practices and dayto-day activities of a society.

People's language, culture and thought are intimately interwoven. In this linguistic anthropological intimacy, language is considered as a social tool with the power to evoke realities beyond the literal linguistic content of what is uttered. According to Duranti (1997) language is a set of symbolic resources connecting the social fabric and the individual representation of actual or possible worlds; a cultural practice and verbal activities that link and fit verbal activities to the real world. Presumably, this is also true of Asu personal names.

Since there is a very close connection between the world, which is reality and the word, which is language, linguistic signs are therefore representations of not only words but also to a greater extent the world. In the study at hand, Asu names are the linguistic signs, while their sociocultural interpretations represent the real world. Since language and sociocultural practices are dynamic, the Asu people and their naming system are eventually affected by this dynamism.

As a manifestation and description of the complexity and diversity of way of life and practices, people's language is itself manifested in various ways. Such ways include their naming systems (the focus of this paper), marriage, family, kinship, political aspects, economic issues, occupational aspects, health systems, religious beliefs and practices, law, funeral activities, etc. Languages also depict issues of power, status, gender, policy, language contact and persuasion.

Linguistic anthropology may also be used to explain how language allows for and creates differentiations between groups, individuals and identities (Duranti, 1997, p. 7). This is the case in sociocultural contexts specificity in the general theoretical frame of anthropology. Though naming is considered as a universal cultural practice where every society in the world give names as tags to its people, it is also specific because how the names are given, the practices and rituals involved and the 
interpretations attached to the names differ from society to society and from one culture to another.

This follows without saying that amid the fact that every society may have their unique naming system, societies with closely related cultures ought to have closely related naming practices. Thus being African, Asu, may share some naming system practices with other African societies though uniqueness among them may still prevail. This means that the probability of African and European naming systems to resemble is very rare.

The study resulting into the current paper was conducted within the premise of the principle of indexicality and specificity of sociocultural contexts. With the principle of indexicality, language is used as a tool through which people's socio-cultural world is constantly described, evaluated and reproduced (Wardhaugh, 2006). Asu naming system is an aspect of cultural indexicality in which personal names are connected to some aspects of the sociocultural contexts of the society. Indexicality, therefore, is applicable in Asu names since they have sociocultural interpretation by referring to personal, temporal, spatial and social deixis.

The names have personal deixis because there is often a person 'grandfather/ mother' whom a child is named after. In most African societies, one can always point to an elderly person, related biologically or distantly, in the society whether dead or alive whose name a younger child bears. Some Asu names carry temporal deixis in the sense that they may indicate the timing of the birth. For instance, kiža for males and nakio for females are given to children who are born at night.

Likewise, there are also spatial names referring to localities within Asu society where a child was born. Social deixis on the other hand refers to the social entities (social status, clan, power and rank) of the referent. Some names clearly depict that the bearer comes from the royal family or from a particular clan. For instance, mnkeni and mbwambo belong to Vankeni and Vabwambo clans respectively.

\section{Empirical Literature Review}

Names refer to purely referential (Rey 1995), and specific elements of human experience i.e. to individuals or collective entities, which they designate or denote. In some philosophical and linguistic viewpoints, names have been characterized logically in the absence of social contexts. Such perspectives consider names as arbitrary labels only that refer to certain signified entries, where the signifier and the signified may not share certain intrinsic qualities. This idea is true when we consider situations where people who bear the same name behave differently.

In every culture, names have sociocultural contexts that identify the bearers. To backup this supposition, Agyekum (2006) quotes Akan maxim;

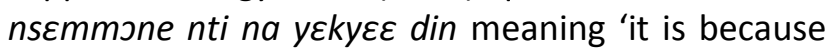
of criminal acts that names were shared'. This is to say that every person in this world has a name that solely identifies and marks him/her from all other peoples in the world. Algeo (1992, p. 728) aptly points out that "People are almost invariably named. Indeed, a human being without a name would be socially and psychologically less than a fully man." In Saussure's notion, the name is the sign and the denotatum is the signified; simply meaning that, the name is a label that refers to a person. Surprisingly, in some Ghananian societies, by default, people who bear the same family name are supposed to be related genetically and so behave alike; this situation disputes the arbitrariness of names.

Obviously proper names refer very specifically (but without describing) to the person who has that name. In this standpoint characterization of names is constant with Saussure's characterization of linguistic signs as arbitrarily connected to their referent (Agyekum, 2006). However, should this assertion be true, then names would have no functional correlation with culture (Rymes, 1996). Inversely, this averment is not exclusively true and thus, not the focus of this paper because the focus here is on cultural significance of Asu names. The paper asserts that names of this society are not arbitrary but are based on socio-cultural and ethnopragmatic contexts.

Various scholars in anthroponomy agree that names have attributes and are attached to referents. This is exactly what pertains in most African cultures where the social and cultural context analyses of personal names strongly reveal the power of names to emphasize social relationships. Personal names are iconic representations of complex social variables that indexicalise and relate to the name and the person. They include sex, hierarchy in birth, circumstances surrounding the birth, timing of the birth, the person's structure, power, status, etc. 
According to Rymes (1996), the events involved in the naming ceremony and the choice of names given to children have traceable links to the referent, meaning that proper names are both "synchronically and diachronically motivated." In African norms, circumstances and social contexts during the birth of a child are fundamental for parents to give a name $X$ instead of $Y$. The circumstantial context will be first and foremost gender, then the socioeconomic situation of the parents and the time of birth and their social links with other people down history, among other factors. These are all aspects of the synchronymy.

The namee then carries this name and since names have social meanings, people expect the bearer to live by it or make positive amends to that name. The varied meanings represent the diachronic aspects of the name. In this respect, it is gainsaying that the meaning of one's proper name evolves through a life history imbued with a lot of transformations and may be intimately linked with the "identity concerns" of an individual or society (Goodenough 1965 , p. 265, Rymes 1996, p. 238). It is also true that with time and evolving sociocultural standings, some individuals may be tempted to modify their names or even to take new names at the expense of the old ones so as to satisfy their self.

According to Akinnaso (1980), the fundamental reason for naming in human society is to provide a symbolic base for social interaction through a formal means of individual identification. Similarly, Mondende (2009) notes that the naming process in African society is to pass a message or information from the name-giver to the entire family and the community at large. According to De Pina-Cabral (2008, p. 5), the 'naming processes carry with them social implications concerning what a person is and how he or she should be placed in the world'.

In other words, naming in African society is to a great extent determined by sociocultural, environmental, circumstantial and ethno-pragmatic contexts (Agyekum, 2006). For example, among the Basotho of South Africa, a child is commonly named after a relative. Hence, names are used to immortalize the ancestors; it is also believed that naming children after ancestors would ensure the inheritance of the social virtues of their grandparents. Also, the Basotho believed that a child is a gift of badimo (ancestors) and thus, a child should be named after a known ancestor as a form of appreciation for a life well spent by the ancestor
(Setiloane, 1976). Naming practices among the Basotho people of South Africa also serve religious, political and social functions (Monnig, 1967).

Accordingly, people expect the namee to live the qualities denoted by a given name because of the inherent power of words ascertained in names to reflect the lives of people either positively or negatively. For example, the Asu expect a child named after a dignitary or a chief to behave properly so that nobody makes derogatory remarks about the name in attempt to denigrate it. Such children are also advised to behave well so as to avoid tarnishing their names. This may conclusively mean that names are meant to shape the children's upbringing, behaviour and socialization.

Names in Asu community often designate the characteristics of the named, at least at the time of birth. No wonder why people may occasionally modify their names or acquire new names and bynames based on their personal achievements. Names can therefore be clearly understood when placed in sociocultural context. Since names are not arbitrary as some may perceive, analysis of proper names should concentrate more on the functional theory bearing the society and culture in mind. Thus, names can be best understood and interpreted under the sociocultural context, meaning that people who know the language and culture of the people are able to interpret such peoples' names accordingly.

This paper is an important contribution to linguistic anthropology and to the study of African anthroponomy and the general theory of onomasiology championed by scholars like Asante (1995), Suzman (1994) and Obeng (2001) among others. The paper is also written with an assumption that "most African societies have similar naming practices that correspond to each other in some ways (Agyekum, 2006). Should Agyekum's assumption be true, further studies on this issue would be used to prove a common origin of the African societies.

\section{Research Methodology}

This section explains about the methodology that guided the study. It presents such items like participants, instruments used to collect data, data collection procedures and data analysis.

\section{Participants}

The nature of the investigation and the instrument used influenced the size and demographics of the 
participants involved. During interview sessions, thirty participants aged $65^{+}$and native Chasu speakers were involved. These elders were judgmentally selected with the assumption that they possess valuable cultural information including meanings of names some of which are not even used today. Ten participants were selected from each of the three villages mentioned in 3 above. Obviously, participant observation made use of more participants as the researcher participated in various activities across the three mentioned villages.

\section{Instruments}

Data collection in this investigation focused not only on enlisting the names but essentially on the meanings of the names as used in Asu society. Data collection exercise was done in three remotely located villages; Vugwama, Mweteni and Bwambo at the southest part of Same District in Kilimanjaro Region. The selection of the villages based on the assumption that cultural practices in these remote areas are not contaminated by cultural contact impact.

Participant observation, in-depth interview and selfintuition were used in the process of data gathering. The interview guide comprised of open ended items focusing on identifying traditional names, their meanings and naming criteria. Participant observation was possible and was efficiently conducted since the researcher is a native speaker of the participants' language. Being a native speaker of Chasu, the researcher used his intuition about names and their meanings in this society. It was also easy to associate with people in their daily activities, rituals, interactions and events to get the needed information in its naturalness.

\section{Data collection Procedures}

In this investigation, interviews were conducted basing on open ended guiding questions so as to elicit naturalistic data from as much free conversation as possible. The interviews involved 20 informants arranged into groups basing on three villages mentioned before. On the other hand, participant observation was used to observe and note down sociocultural behaviour in context with the researcher behaving like a member of the studied community. The researcher easily and effectively participated in various socio-economic, cultural and traditional activities of the people involved in this project as he himself is a member of the speech community, born and raised up in the area till secondary school going age and has had constant interactions with the people since then. Observations were therefore done without spending much time to establish rapport with the respondents

\section{Data Analysis}

In managing the data, thematic analysis techniquea flexible data analysis plan that qualitative researchers use to generate themes from interview data (Braun and Clarke, 2013)- was applied, which involved grouping the names into various categories basing on meanings and projected connotation as well as naming criteria. Accordingly, the findings are presented in subsequent sections in descriptions and explanations. The presentation and discussion based on the typology of names in Asu society encompassing family names and circumstantial names, to mention but few.

\section{Analysis and Discussion}

There is a consensus among anthropological writers that naming practice is generally a valued culture among African people (Mohome, 1992; Yusuf, Olatunji, \& Issah, 2014), thus, given names are so relevant that some of their socio-cultural characteristics cannot be well understood except one peeps into the dynamic nature of their naming. The study at hand has revealed that nature of naming in Africa is bore out in the fact that a name given to a child or an adult (for example nickname) is often determined by different factors ranging from belief in individual spirit, belief in reincarnation, environment, social class, lineage system, ethnic affiliation, gender, day of the week, day of the month, time of the year, conditions of parents at birth, conditions of child at birth and circumstances surrounding the birth, historical events, family occupation, family deity, family name and economic situation, to mention but few. It is in this line of reasoning that the findings are presented.

\section{Typology of Asu Names}

This sub-section presents the typology of personal names in Asu speech community. It is an empirical and sociocultural descriptive study of names that exist in this community. Considering both purely traditional and contemporary names, the description gives the translations and the ethnography background of the names. The section goes on to exemplify the impact of western culture, in the umbrella of religion and modernity in system and practices. A highlight is also made on the 
implications of the naming practices, especially in gender relations.

\section{Family names}

In most African communities, family names are clan names given to children by their fathers, traditionally after discussion with the grand parents of the new born. However, nowadays, the mother of the child is also involved in the discussion. Among the Asu people today, family name is a reference to the child's grandmother/ grandfather or any other important person like clan leader 'mfumwa' etc. Table 1 illustrates family names specifically indicating a clan from which the named descends

Table 1 Asu Family Names

\begin{tabular}{ll}
\hline \multicolumn{1}{c}{ Name } & \multicolumn{1}{c}{ Appellation } \\
\hline Mbwambo & descends from Vabwambo clan or born in Bwambo locality \\
Mnkeni & descends from Nkeni clan \\
Mchome & descends from Vachome clan or born in Chome locality \\
Mnzava & descends from Vanzava clan \\
Mmbagha & descends from Vambagha clan or born in Mbagha locality \\
Mndeme & descends from Vandeme clan or born in Ndeme locality \\
\hline
\end{tabular}

Table 2 Asu Anthrotoponyms

\begin{tabular}{lll}
\hline \multicolumn{1}{c}{ Name } & \multicolumn{1}{c}{ Meaning } & \multicolumn{1}{c}{ Appellation } \\
\hline mweta & river & male child born at/ near the river \\
namweta & pertaining to river & female child born at/ near the river \\
nzira/ nzia & path & male child born on the way \\
nanzia & pertaining to path & female child born on the way \\
izungo & bush & male child accidentally born in the bush \\
kapara & grassy compound & male child born on grassy ground \\
kiete/ nakiete & market & female child born at the market place \\
\hline
\end{tabular}

Though most Bantu languages are not grammatically gendered, most societies are patriarchy in nature, a social relation system that favors men at the expense of women. This is evidently visible in Asu family names where only male newborns can acquire clan names as first name; female newborns will use clan names as surnames only. This shows patriarch nature of Asu people at work. Generally, family names are derived from the patrilineal clans of the fathers, hence used as social tags to indicate not only personal but also in most cases group identity.

\section{Circumstantial Names}

There are certain names which are given basing on the circumstances surrounding the birth of a child. These may relate to the places of birth, period of time, festivals or sacred days, manner of birth, etc. Sometimes the circumstances are not directly related to the newborn but rather to an ancestral figure; grandfather or grandmother. In Asu community, these names can be grouped into four for a better understanding: (a) anthro-toponyms, (b) temporonyms, (c) manner of birth, and (d) death prevention and survival names.

\section{Anthro-Toponyms}

In this study anthro-toponyms are personal names that pertain to the place of birth of the child. The place may even refer to the farm or along the way when the woman was travelling to another place. It is also possible to use the names of physical features or other geographical areas nearing the birth place as names for children. Unlike family names, anthrotoponyms can be given to both sexes though as described before, gender imbalance is still evident in most names. Table 2 illustrates some of anthrotoponyms.

\section{Temporonym}

The term temporonym is used for names that relate to the period of birth. In Asu community, there are no traditional birthday names. Therefore, what is often denoted is the timing of the birth. In some instances the names may also depict seasons during which the birth occurs. Just like in the case of anthrotoponyms, newborns may be given temporonyms not necessarily because of the timing of their birth but because it is a tribute to their grandparents. Table 3 exemplifies some few temporonyms in Asu society. 
Some temporonyms are given to mark or remember a notable event in the family or clan. This kind of periodic names is very important not only to the name but imperatively to the entire community as they point back to crucial historical and cultural phenomena of the society. The events may denote happiness (various celebrations), sadness (war, famine, etc.) or even suffering. Table 4 illustrates some of such names.
Manner of birth is another category of circumstantial names in Asu community denoting situation surrounding the whole birth processes. Such conditions may be joyous, challenging, frustrating or surprising. The presence of this subcategory of personal names in Asu explains a belief among the people that whatever happens during the birth process has a meaning, either to the parents or destine of the newborn. Some few names of this sub-category are exemplified in table 5 .

Table 3 Asu Temporonyms

\begin{tabular}{lll}
\hline \multicolumn{1}{c}{ Name } & \multicolumn{1}{c}{ Meaning } & \multicolumn{1}{c}{ Appellation } \\
\hline Kio/Kiža & night/ darkness & male child born during the night \\
Nakio & pertaining to night & female child born during the night \\
Namsi & pertaining to day & female child born during the day \\
Mashika & long rainy season & male child born during "mashika" sowing period \\
\hline
\end{tabular}

Table 4 Temporomyms marking notable events/ moments

\begin{tabular}{lll}
\hline \multicolumn{1}{c}{ Name } & \multicolumn{1}{c}{ Meaning } & \multicolumn{1}{c}{ Appellation } \\
\hline nkondo & war & male child born when the clan was involved in a war \\
nankondo & pertaining to war & female child born when the clan was in a war \\
nzighe & locusts & male child born during locusts inversion \\
nanzighe & pertaining to locusts & female child born during locusts inversion \\
ngasu & Initiation & male child born during initiation ceremony \\
nangasu & pertaining to initiation & female child born during initiation ceremony \\
\hline
\end{tabular}

Table 5 Names depicting birth circumstances

\begin{tabular}{lll}
\hline \multicolumn{1}{c}{ Name } & \multicolumn{1}{c}{ Meaning } & \multicolumn{1}{c}{ Appellation } \\
\hline kimako & surprise & a newborn (usually male) coming as a surprise \\
singano & needle & male child born with extraordinary slander body \\
nakadori & related to 'little' & a newborn (usually female) with little weight/ size \\
kighera & iron & male child born through prolonged and problematic labour male \\
& & child who is anticipated to be as strong as iron \\
\hline
\end{tabular}

A sub category of such names connected to the manner of birth could be described in terms of the nature of the marital status of the child's parents. Asu people believe that '(legal)' children are to be delivered in an accepted marriage union, otherwise the children are referred to as 'illegal.' In some few clans, such children born outside the holy matrimony were traditionally named nzune and nanzune for male and female respectively. However, this kind of naming is not active nowadays because of cultural contact with the outside world.
Flora and Fauna; and Physical Structure Names

Certain Asu personal names are derived from flora and fauna. In most cases, it is their physical structures and their behavior that are compared. Such names are usually given to a new born by referring back to the behavior of an ancestral figure with anticipation that the child inherits not only the name but will also take with him/her the behavior of their respective grandparents. Table 6 exemplifies animal names that can be occasionally given to newborns.

Table 6 Asu Fauna Names

\begin{tabular}{lll}
\hline \multicolumn{1}{c}{ Name } & \multicolumn{1}{c}{ Meaning } & \multicolumn{1}{c}{ Appellation } \\
\hline kitojo & hare & a male child anticipated to be clever like a hare \\
kanyawi & cat & a male child anticipated to be trickier like a cat \\
kagoswe & 'little' rat & a child (female) anticipated to be stubborn as a rat \\
itaa & big wild beast & a male child whose ancestral figure was very strong \\
nguve & pig & a male newborn anticipated to be as greed as a swine \\
nanguve & pertaining to pig & a female newborn anticipated to be as greed as a swine \\
\hline
\end{tabular}

26 East African Journal of Education and Social Sciences (EAJESS) 1(2)20-29 
Table 7 Asu Flora Names

\begin{tabular}{lll}
\hline \multicolumn{1}{c}{ Name } & \multicolumn{1}{c}{ Meaning } & \multicolumn{1}{c}{ Appellation } \\
\hline muodo & herbal plant & male child whose ancestral figure was a herbalist \\
ikumbo & taro plant leaf & female child born in an area with a lot of taro plants \\
nkinda & banana tree & male child born in a banana shamba \\
madafa & dry banana backs & male child born during dry season when dry banana backs are \\
& & plenty and harvested for housing purposes \\
\hline
\end{tabular}

There are few individuals with flora names that can be cited in Asu society today. This is probably because of cultural contact with most people now preferring western/Christian names at the expense of traditional ones.

\section{Theophoros Names}

In Asu society, just like in many other cultures, there is a belief that what happens in the society is dictated and controlled by a personality outside the horizons of human beings. In many African societies this could be a traditional spiritual leader believed by all members of the society. A good example could be taken from Akan, a West African society in which there is a belief that if a mother suffers constant child mortality, it is the child's mother in the underworld that does not want the child to stay in the living world. To combat such an unfortunate situation, the parents give the child a weird name. They believe that if the name is unattractive, the other mother in the underworld will not like to accept the child over there and this would make the child stay.

Table 8 Theophoros names

\begin{tabular}{lll}
\hline Name & Gender & Appellation \\
\hline togolani & male & keep praising \\
nakaza & male & I praise (I've praised) \\
mkazeni & male & praise Him \\
arirani & male & trust \\
gwirisha & male & hold firm (the faith) \\
natogola & female & l've praised \\
\hline
\end{tabular}

However, due to contact with western Christian culture, things are different in a handful of African culture where this personality is now referred to as God. In this case, newborns are given names which glorify, praise or give thanks to the said. This is the case with Asu society as exemplified hereunder.

\section{Christianized/ Modernized Asu Names}

This study has also noted that many people in Asu society, especially the younger/ modern generation are no longer interested in traditional names. Some traditional names have therefore been translated chiefly into Kiswahili- a Bantu language spoken as a lingua franca all over Tanzania- so they can sound less traditional. This probably translates negative attitude of the people towards their own traditions. The following example lists some of the Asu names which have been translated to Kiswahili, resulting into a mixture of Asu and Swahili in the sense that while they do not sound purely Swahili because of tonal and other syntactical modifications, they also sound less traditional.

Table 9 Asu names translated to Kiswahili

\begin{tabular}{lll}
\hline \multicolumn{1}{c}{ Asu name } & \multicolumn{1}{c}{ Meaning } & \multicolumn{1}{c}{ Translated } \\
\hline mntambo/ & $\begin{array}{l}\text { sojourner/ } \\
\text { traveller }\end{array}$ & msafiri \\
mcharo & be happy & furahini \\
zihirwani & hold firm/trust & imani, aminieli \\
gwirisha & love & upendo/ pendo \\
lukundo & pray/worship & ombeni \\
tasani & bush & kisaka (kichaka) \\
izungo & Desire/hope & tumaini \\
kiariro/ arirani & & \\
\hline
\end{tabular}

It was also found that some people do not just translate their names but they seek and eventually acquire new western names, especially during initiation in the name of baptism in Christianity. Some of such names which usually relate the named to their new faith are exemplified here under in table 10.

The illustration on tables 9 and 10 defines the extent to which Asu traditions have been negatively impacted by cultural contact. As it could be seen in the field, in most clans/ families, some people are not comfortable with their traditional names and they are barely given to newborns, with the exception of few individual to which tradition still matters. Remarkably, it is also evident that even where such traditional names are given, the bearers would still temper with them as they grow up. In school, for instance, children dare even to change their traditional names in favour of Swahili or English names as they would like to be perceived modern and up-to-date.

\section{Gender relations in Asu names}

societies are patriarchy in nature, a system in which masculine gender is emphasized usually at the expense of feminine. This circumstance is seen in 
many circles of life including traditional leadership, traditional wealth ownership and inheritance, language forms and functions and even in the naming system. In naming, just like most examples shown, women are marginalized in the sense that most female names are derived from male names by the means of prefixation as indicated in table 11 , to mention but few.

Table 11 Women names derived from men's

\begin{tabular}{ll}
\hline \multicolumn{1}{c}{ Male name } & Derived female name \\
\hline mweta & namweta/ namwete \\
nzira/ nzia & nanzia \\
ngasu & nangasu \\
nkondo & nankondo \\
nzinge & nanzighe \\
\hline
\end{tabular}

\section{Conclusions}

This paper is an aspect of linguistic anthropology and is based on the assumption that there is a strong connection between people's language and their cultural practices. The emphasis is on how language is used as cultural resources and practices; and how it is viewed as a powerful tool used to view and understand the worldview and philosophy of a particular society. Thus, this goes without saying that language is used as a microscopic lens to view and understand the social practices and day-to-day activities of a given society.

Asu personal naming system and practice, just like in other cultures, is a marker of the people's belief, ideology, religion, culture, philosophy and thought. The names are best understood and analysed when one has insight into the ethno-pragmatics, sociocultural norms, the language and culture of the Asu. The names are therefore not only an aspect of linguistic relativity but also refer to elements of Asu human experience and ways of life in a philosophical sense. This paper went on to stressing that names are not mere arbitrary and meaningless labels but rather have indexical relationship to socio-cultural meanings and functions, places, time, people and events.

Traditionally, Asu people believe that there is some inherent power and linkage in names, and expect the names to reflect and indexicalise the lives and behavior of people either positively or negatively. This is the case especially when the name refers back to an earlier ancestral figure. Individual's name is of concern not to themselves but to the whole society, for the individual performs and participates in the society.
Accordingly, Asu typology of names indicates various contexts such as family, circumstantial, manner of birth, flora and fauna, markers of notable events, theophoros names and western names resulting from cultural contact. It is also worth noting that every potential Asu has at least two of these names: one's own name plus a family (or rather an ancestral) name. It is also possible for a person to accumulate some other names especially baptismal (mostly Christian and partly Muslim) names as $\mathrm{s} /$ he grows up in the society.

Asu naming practices have also revealed the patriarchy socio-cultural system emphasizing male dominance at the expense of female. Only Asu men for instance can acquire family names as personal names while women use family names only as surnames. It is also worth noting that most Asu female names are simply derived from male names, another clear evidence of male dominance.

\section{Recommendations}

This paper has made it clear that Asu personal names are an important area of the Asu culture that should not be ignored in any sociolinguistic and anthropological studies. It is also clear that naming system is a multidisciplinary area of study for scholars in sociology, history, religion, anthropology, linguistics, ethnography and philosophy. It is therefore revealed to the respective scholar that a lot can still be investigated about personal names in Asu society. Areas such as the place of names in social relation and traditional religion, historical view point of traditional names, etc. may be investigated further.

The paper has also revealed that traditional naming system is threatened by modern naming patterns as the modern generation prefers Kiswahili, Christian or Western names at the expense of Asu traditional names. This calls for strategic measures to be taken to prevent the disappearance of this important cultural aspect. Programmes aiming at raising people's awareness about the importance of their culture are to be organized. More documentation on this and other cultural aspect of the society is another crucial strategy for preserving the cultural dimensions of the people. Since Asu naming system has also revealed gender imbalance where most traditional female names are derived from male names, this calls for studies on whether this has a place in socioeconomic and political power imbalance among Asu people for respective measures. 


\section{Reference}

Abdulganiy, O., Moshood, I., Yusuf N., Muhammed, A.Y., \& Abdul-Rasheed, S. (2015) Persona I Name as a Reality of Everyday Life: Naming Dynamics in Select African Societies, The Journal of Pan African Studies, 8(3), 93-105

Agyekum, K. (2006). The Sociolinguistic of Akan Personal Names, Nordic Journal of African Studies 15(2), 206-235.

Akinnaso, N.F. (1980). "The Socio linguistic basis of Yoruba personal names" Anthropological Linguistics, 22(7), 275-304.

Asante, M. K. (1995). The Book of African Names. Trenton: Africa World Press.

Batibo, H. M. (1992), "The Fate of Ethnic Languages in Tanzania". In Matthias Brenzinger (ed) Language Death: Factual and Theoretical Explorations with Special Reference to East Africa. Berlin: Mouton de Gruyter.

Braun, V., \& Clarke, V. (2013). Successful qualitative research: A practical guide for beginners. New York; Sage.

Goodenough, W. (1965). 'Personal Names and modes of address in two Oceanic Societies.' In: Context and Meaning in Cultural Anthropology, Melford Siro (ed.), pp. 26576. New York: Free Press.

Kileng'a, A. F. (2015). The Implications of Bilingualism on Southern Chasu. Saarbrücken: Lambert Academic Publishing.

Lewis, M. P. (2012). Ethnoloque: Languages of the World. $17^{\text {th }}$ Edition. Dallas: SIL International. [http;/www.ethnoloque.com/] retrieved on 01/08/2011.

Mairi, R., \& George, D. (2005). Chambers 21st century dictionary India: Allied publishers private limited.

Mohome, P. M. (1992). Naming in Sesotho: its sociocultural and linguistic basis New York: University College.
Monnig, H. D. (1967). The Pedi. Pretoria: Van Schaik.

Mreta, A. Y. (1998), An Analysis of Tense and Aspect in Chasu. Their Form and Meaning in the Affirmative Constructions. (Beitrage zur Africanistik; 10) Zulg Bayreuth, University Dissertation.

Neething, B. (2004). "Name Choice among the Xhosa of South Africa" The language quarterly, xxix (4), 4-6.

Obeng Gyasi, S. (2001). African Anthroponymy: An Ethnopragmatic and Morphophonological Study of Names in Akan and Some African Societies. Muenchen: Lincom Europa.

Rey A. (1995). Essays on Terminology. Amsterdam: John Benjamins Publishing Company.

Rymes, B. (1996). Naming as social practice: The Case of Little Creeper from Diamond Street. Language in Society 25: 237-260.

Sebonde, R. Y. (2009), A Sociolinguistic Analysis of Variation in Rural African Community Chasu in Same District, Tanzania. Ph.D. Thesis: University of Csape Town.

Setiloane, G. (1976). The image of God among the Sotho-Tswana. Netherlands, A.A: Balkema.

Suzman, S. M. (1994). Names as Pointers: Zulu Personal Naming Practices. Language in Society 23: 253-72.

Wardhaugh, R. (2006), An Introduction to Sociolinguistics -Fifth Edition, Malden: Blackwell.

Yusuf, N., Olatunji, A., \& Issah, M. (2014). "Yoruba names as reflection of people's cultural heritage". In S. A. Ahmad et.al (ed.), Bringing our cultures homes: Festschrift for Bade Ajayi at 70 (pp. 186-196). Ilorin: Chridamel Publishing House. 